\title{
Factors Associated with Relapse of Schizophrenia in Bangladesh
}

\author{
Md Kamrul Hassan ${ }^{1}$, Md Inamul Islam², Abul Hossain Muhammad Kazi Mostofa Kamal ${ }^{3}$, \\ Md Julfikkar Alam ${ }^{4}$ \\ ${ }^{1}$ Department of Psychiatry, Combined Military Hospital, Sylhet, Bangladesh \\ ${ }^{2}$ Department of Psychiatry, Combined Military Hospital, Rangpur, Bangladesh \\ ${ }^{3}$ Department of Psychiatry, Combined Military Hospital, Dhaka, Bangladesh \\ ${ }^{4}$ Combined Military Hospital (CMH), Sylhet, Bangladesh
}

\section{Email address:}

khassan1461@gmail.com (Md K. Hassan)

\section{To cite this article:}

Md Kamrul Hassan, Md Inamul Islam, Abul Hossain Muhammad Kazi Mostofa Kamal, Md Julfikkar Alam. Factors Associated with Relapse of Schizophrenia in Bangladesh. American Journal of Psychiatry and Neuroscience. Vol. 8, No. 3, 2020, pp. 60-64. doi: $10.11648 /$ j.ajpn.20200803.14

Received: August 21, 2020; Accepted: September 1, 2020; Published: September 10, 2020

\begin{abstract}
Context: In the face of increasing number of relapse cases of schizophrenia, sufficient work is not available in Bangladesh. Aims: To find out the common factors of relapse of schizophrenia in Bangladesh and to find out the relationship of relapse of schizophrenia with sociodemographic characteristics. Settings and Design: Cross-sectional descriptive study; Department of Psychiatry, Combined Military Hospital, Dhaka, National Institute of Mental Health (NIMH), Dhaka and Psychiatry department of Bangabandhu Sheikh Mujib Medical University (BSMMU), Dhaka. Materials and Methods: Data from 50 relapse patients receiving treatment of schizophrenia were collected, from April 2018 to September 2018. Statistical Analysis Used: The data were processed and analyzed with the help of computer program SPSS (Statistical Package for Social Sciences) win version 16. Results: The mean age was $31.16( \pm 10.59)$ years ranging from 14 to 55 years. Majority of the respondents $70 \%$ $(n=35)$ were under 35 years. 62\% $(n=31)$ of the respondents were male and $38 \%(n=19)$ were female. 96\% ( $=48)$ of the respondents were Muslims. $52 \%(n=26)$ of the respondents were married and $46 \%(n=23)$ were unmarried. $46 \%(n=23)$ were from rural background and 54\% $(\mathrm{n}=27)$ of the respondents were from urban background. $40 \%(\mathrm{n}=20)$ of the respondents were from lower class, $52 \%(\mathrm{n}=26)$ were from middle class, and only $8 \%(\mathrm{n}=4)$ were from higher class. $56 \%(\mathrm{n}=28)$ of the respondents had perceived stressful life events and $44 \%(n=22)$ of the respondents had no such history. $52 \%(n=26)$ of the patients had experienced high expressed emotion and 48\% $(\mathrm{n}=24)$ had low expressed emotion. Among the 50 relapsed schizophrenia patients, only $26 \%$ $(n=13)$ had full compliance, $30 \%(n=15)$ had full noncompliance and rest had partial compliance. There was no significant relationship between educational status and medication compliance in the current study. The study revealed significant association with lower social class and presumptive stressful life events. Conclusions: This study highlighted the perceptions of schizophrenic patients and their caregivers about factors that influence relapse. It indicated that stressful life events, high expressed emotion, and non-compliance to medication had a role in relapse. This study provides information about socio-demographic and other related factors which can offer important guideline for future study. Adherence to antipsychotic medication, reducing high expressed emotion and stressful life events protect patients from relapse.
\end{abstract}

Keywords: Schizophrenia, Factor, Relapse, Prevention

\section{Introduction}

Schizophrenia is a major mental health problem which is often difficult to manage and yet poorly understood. It afflicts a sizable population over the world. The worldwide prevalence of schizophrenia is about 1\%. [1] In Bangladesh, prevalence of schizophrenia is found to be $2.4 / 1000$ population in a detailed study of rural population adjacent of Dhaka city which is comparable with India prevalence rate. [2] Non-compliance rate with antipsychotic medication is 
high. Eighty percent of schizophrenia receiving antipsychotic medication fail to comply with treatment. Psychotic relapse is known to be closely linked to noncompliance to drug. Long term antipsychotic treatment has been shown to be effective in preventing relapse but even with continuous medication, about $40 \%$ of patient relapse during first year of discharge from hospital, compared with about $70 \%$ of patient taking placebo. The high rate of relapse in spite of continuous medication have stimulated research on other cause of relapse. Apart from medication non-compliance, social stressors (life events, unfavorable family atmosphere) seem to be important. The result of various studies has contributed to the development of 'relative's expressed emotion', which influence the relapse of schizophrenia. It is often accompanied by relapse even while on treatment. [3] Relapse rates vary from $50 \%$ to $92 \%$ and are similar in developed and developing countries, despite the former having wellestablished mental health services. [4] Internationally, the factors commonly associated with relapse include poor adherence to treatment, substance abuse, co-morbid psychiatric illness, a co-morbid medical and/or surgical condition, stressful life events, and the treatment setting. [5] this study is designed to assess the factors associated with relapse of schizophrenia in Bangladesh.

\section{Materials and Methods}

This cross-sectional descriptive study was conducted from April 2018 to September 2018 at Department of Psychiatry, Combined Military Hospital, Dhaka, National Institute of Mental Health (NIMH), Dhaka and Psychiatry department of Bangabandhu Sheikh Mujib Medical University (BSMMU), Dhaka. For demographic assessment, a semi-structured questionnaire was prepared by the interviewer after taking informed written consent. A series of 50 relapse patients of schizophrenia was taken by purposive convenience sampling method. Data was processed and analyzed with the help of computer program SPSS (Statistical Package for Social Sciences) windows version 16. Quantitative data was expressed as mean and standard deviation and qualitative data as frequency and percentage. Comparison was done by Chi-Square $\left(\chi^{2}\right)$ test and unpaired t-test where necessary. Risk factors was determined using Odd Ratios.

\section{Results}

The mean age of the study group was $31.16( \pm 10.59)$ years ranging from 14 to 55 years. Majority of the respondents $(70 \%)$ were under 35 years. Distribution of respondents according to sex revealed that $62 \%$ of the respondents $(n=31)$ were male and rest $38 \%$ were females $(n=19)$. The educational status of the respondents was found about $8 \%$ were illiterate, $4 \%$ were below class five, $24 \%$ were studied from class six to ten, $52 \%$ were attained SSC and HSC and $12 \%$ had graduated and above. One in four respondents were unemployed, $30 \%$ were student, $24 \%$ were housewives, $16 \%$ were service holder and $6 \%$ were farmer. The marital status of the respondents revealed $52 \%$ of the respondents were married and $46 \%$ were unmarried.

The study also revealed the perceived stressful life events among the respondents. About $56 \%$ of the respondents had stressful life events and rest (44\%) had no such history.

Table 1. Distribution of Stressors among the respondents $(n=50)$.

\begin{tabular}{lll}
\hline Name of the Stressor & Frequency & Percent \\
\hline Death of near relatives & 2 & 4 \\
Marital conflict & 7 & 14 \\
Death of friends & 1 & 2 \\
Theft/Dacoity & 1 & 2 \\
Affair breakup & 1 & 2 \\
Major physical illness & 1 & 2 \\
Money loss & 4 & 8 \\
Illness of family member & 1 & 2 \\
Familial conflict & 5 & 10 \\
No friends & 1 & 2 \\
Stopping school & 1 & 2 \\
Altered sleep & 1 & 2 \\
Altered social activities & 2 & 4 \\
\hline
\end{tabular}

Distribution of stressors among the study population is shown in Table 1.

The study found out the distribution of expressed emotion in the family of the relapsed schizophrenic patients. About $52 \%(n=26)$ of the respondents had high expressed emotion. It also explored the relationship of family history of mental illness with expressed emotion which found no significant association with history of mental illness with expressed emotion.

The distribution of high expressed emotion along with family history of psychiatric illness is shown in Table 2. Distribution of presumptive stressful life events and compliance among the respondents is shown in Table 3. The study found that, among the 50 relapsed schizophrenia patients, only $26 \%$ had full compliance, $30 \%$ had full noncompliance and rest (44\%) had partial compliance.

Table 2. Distribution of expressed emotion and family history of psychiatric history the respondents $(n=50)$.

\begin{tabular}{llll}
\hline Family History of Psychiatric illness & High Expressed Emotion & Low Expressed Emotion & Total \\
\hline Yes & $11(50 \%)$ & $11(50 \%)$ & 22 \\
No & $13(46 \%)$ & $15(64 \%)$ & 28 \\
Total & $24(48 \%)$ & $26(52 \%)$ & 50 \\
\hline
\end{tabular}

\section{Discussion}

Schizophrenia is a chronic and disabling illness, with the majority of patients experiencing multiple relapses during the course of the illness. Relapse increases the economic burden on health care systems because of its associated morbidity and re-admissions to hospital. Prevention of relapses could 
have significant therapeutic and socio-economic implications

Causes of relapse is noncompliance to drug, loss of medication efficacy, high expressed emotional relative and stressful life events. Multiple factors contribute to increasing the risk of relapse. In a systematic review and meta- analysis of longitudinal studies it was found that non-adherence with medication, carers' criticism and poorer premorbid adjustment significantly increased the risk for relapse in firstepisode psychosis. [6]

Table 3. Distribution of presumptive stressful life events and compliance among the respondents $(n=50)$.

\begin{tabular}{|c|c|c|c|c|}
\hline \multirow{3}{*}{$\begin{array}{l}\text { Social Class } \\
\text { Lower class }\end{array}$} & \multirow{3}{*}{$\begin{array}{l}\text { Stressful life events } \\
\text { Yes } \\
\text { No }\end{array}$} & \multicolumn{2}{|c|}{ Frequency (n) } & \multirow{3}{*}{$\begin{array}{l}\text { Percentage (\%) } \\
40\end{array}$} \\
\hline & & 16 & 20 & \\
\hline & & 4 & 20 & \\
\hline \multirow{2}{*}{ Middle class } & Yes & 11 & \multirow{2}{*}{26} & \multirow{2}{*}{52} \\
\hline & No & 15 & & \\
\hline \multirow{2}{*}{ Higher class } & Yes & 1 & \multirow{2}{*}{4} & \multirow{2}{*}{8} \\
\hline & No & 3 & & \\
\hline \multicolumn{2}{|l|}{ Compliance } & \multicolumn{2}{|c|}{ Frequency } & Percentage (\%) \\
\hline \multicolumn{2}{|c|}{ Complete disagree } & \multicolumn{2}{|l|}{15} & 30.0 \\
\hline \multicolumn{2}{|c|}{ Partial disagree } & \multicolumn{2}{|l|}{7} & 14.0 \\
\hline \multicolumn{2}{|c|}{ Undesired agree } & \multicolumn{2}{|l|}{7} & 14.0 \\
\hline \multicolumn{2}{|c|}{ Sometimes disagree } & \multicolumn{2}{|l|}{3} & 6.0 \\
\hline \multicolumn{2}{|l|}{ Silent agree } & \multicolumn{2}{|l|}{4} & 8.0 \\
\hline \multicolumn{2}{|c|}{ Little participation } & \multicolumn{2}{|l|}{1} & 2.0 \\
\hline \multicolumn{2}{|c|}{ Completely agree } & 13 & & 26.0 \\
\hline
\end{tabular}

According to analysis the mean age was $31.16(\mathrm{SD} \pm 10.59)$ years ranging from 14 to 55 years. Majority of the respondents $(70 \%)$ were under 35 years. Distribution of relapse case respondents according to sex revealed that $62 \%$ of the respondents were male and rest were females. One study showed Schizophrenia is generally reported to be slightly more frequent in men than in women, with a risk ratio of $1.4 / 1$. The disorder is also more severe in men. [7] In addition, men tend to develop severe schizophrenia earlier than women; the peak age of onset of frank psychotic symptoms is 20-24 years in men, but 5 or more years later in women. [8-10]

Distribution of religion of the respondents revealed $96 \%$ of the respondents were Muslims. The educational status of the respondents was found about $8 \%$ were illiterate, $4 \%$ were below class five, $24 \%$ were studied from class six to ten, $52 \%$ were attained SSC and HSC examination, and 12\% had graduated and above.

The occupational status was found about one in four respondents were unemployed, $30 \%$ were student, $24 \%$ were housewives, $16 \%$ were service holder and $6 \%$ were farmer.

The marital status of the respondents revealed about $52 \%$ of the respondents were married and $46 \%$ were unmarried.

Residence of the respondents was found $46 \%$ were from rural background and $54 \%$ of the respondents were from urban background. Schizophrenia is most common in disadvantaged areas of inner cities, a finding first noted in Chicago in 1939. This association was recently replicated in an epidemiological study in England, the Aetiology and Ethnicity in Schizophrenia and Other Psychoses (AESOP) study, which reported that the incidence of schizophrenia in the smaller cities of Nottingham and Bristol was less than half of that in London.
The highest rates of people with schizophrenia in London were in areas with the lowest social cohesion, a finding that was also reported in the original Chicago study. [11, 12]

Here $40 \%$ of the respondents were from lower class, $52 \%$ were from middle class, and only $8 \%$ were from higher class. Relapse in lower and middle social class might be due to poor economic condition, social stigma and ignorance.

In the study found that among the 50 relapsed schizophrenia patients, only $26 \%$ had full compliance, $74 \%$ had noncompliance. The rate varied from different studies and in Egypt it was 74\%. [13] Another study in Bangladesh depicted about $87 \%$ of the respondents were non-compliant to medications which can be explained by psychopathology of the disorder itself, poor health literacy, and poor status of psychoeducation. [14] After 1-2 years of being well on antipsychotic medication, the risk of relapse remains high (figures of $10-15 \%$ per month have been quoted), but this area is less well researched. [16] Other studies in first episode patients have found that discontinuing antipsychotics increases the risk of relapse 5-fold and confirmed that only a small minority of patients who discontinue remain well 1-2 years later. [16-20] A comprehensive review 73 reported that the rate of medication non-adherence in patients with schizophrenia is as high as $40 \%-50 \%$.

In this study 5 revealed the medication compliance affectivity by the educational attainment on the respondents. There was no significant relationship between educational status and medication compliance in the current study.

The factors consistently associated with non-adherence in patients with schizophrenia are lack of insight, attitudes towards their illness and the medication, past experiences with their illness and its treatment, substance abuse, adverse drug reactions and lack of social support. [21-23]

The distribution of expressed emotion in the family of the relapsed schizophrenic patients revealed about 52\% had high expressed emotion and $48 \%$ had low expressed emotion. Previous studies found that prevalence of high expressed emotion in urban London and California were $57 \%$ and $67 \%$ respectively, but $23 \%$ in India. [24] Expressed emotion has been extensively studied and has been found to be a robust and significant predictor of relapse in schizophrenia. [25]

The study explored the relationship of occupation with expressed emotion. The current study revealed no significant association of occupation with expressed emotion. This study also explored the relationship of family history of mental illness with expressed emotion. The current study revealed no significant association with history of mental illness with expressed emotion.

The distribution of perceived stressful life events among the respondents was fond about $56 \%$ of the respondents had stressful life events and rest of the respondents had no such history.

People with psychosis also report an increased rate of particularly intrusive life events, such as assault, before the onset of illness. [26] Whether these environmental factors are independent risk factors is debated.

The relationship of social class with presumptive stressful 
life events, the current study revealed significant association with lower social class and presumptive stressful life events where $\mathrm{p}=0.016$ (revealed by Chi square test).

One of the important factor is stressful life event which can relapse schizophrenia. People with schizophrenia are subject of many adverse effects from the social environment, which upset their social adaptation. [27] This is a prerequisite, for a life in a chronic stress with the all following consequences, mostly related to the progress of the schizophrenia.

Development of concomitant diseases and higher mortality rate. [28] There are studies that indicate that people with schizophrenia are more vulnerable from the impact of the social stress in comparison with mentally healthy people. [29] These studies correlate with others similar to them and thus show the relation between stressful factors and the severity of the clinical manifestation of the disease. [30] From the other side there are opinions that because of the disease and the related with it "perception of the world" these patients are distant from the social failures and respectively they don't show the expected "poor" quality of life. [27]

\section{Conclusion}

This study highlighted the perceptions of patients with schizophrenia and their caregivers about factors that mostly influence relapse. Despite recent therapeutic progress, relapse in schizophrenia is a common and major problem among Bangladeshis. The study indicated that stressful life events, high expressed emotion, and non-compliance with medication had a role in schizophrenic patients for its relapse This study provides information about socio-demographic and other related factors which can offer important guideline for future study.

\section{References}

[1] Davis LM, Drummed MF. The economic burden of schizophrenia. Psychiatry Bulletin. 1990; 14: 522-525.

[2] Chowdhury AKMN, Alam MN, Ali SMK. Dasher kandi Project Study: Demography, Morbidity and mortality in a rural area of Bangladesh. Bangladesh Medical Research Council Bulletin. 1981; 7 (1): 22-39.

[3] Leff J, Wig N, Ghosh A et al. The influence of relatives' expressed emotion on the course of schizophrenia at Chandigarh in India. Br J Psychiatry. 1987; 151: 166-173.

[4] Suzuki Y, Yasumura S, Fukao S, et al. Associated factors of rehospitalization among schizophrenic patients. Psychiatry Clin Neurosci. 2003; 57: 555-561.

[5] Harris MG, Henry LP, Harrigan SM, et al. The relationship between duration of untreated psychosis and outcome: an eight-year prospective study. Schizophr Res. 2005; 79: 85-93.

[6] Alvarez-Jimenez M, Priede A, Hetrick SE, Bendall S, Killackey E, Parker AG, et al. Risk factors for relapse following treatment for first episode psychosis:a systematic review and meta-analysis of longitudinal studies. Schizophr
Res. 2012; 139: 116-128.

[7] Castle DJ \& Murray RM. The neurodevelopmental basis of sex differences in schizophrenia. Psychol Med. 1991; 21: 565-575.

[8] Castle D, Sham P \& Murray R. Differences in distribution of ages of onset in males and females with schizophrenia. Schizophr Res. 1998; 33: 179-183.

[9] Eranti SV, MacCabe JH, Bundy H \& Murray RM. Gender difference in age at onset of schizophrenia: a meta-analysis. Psychol Med. 2013; 43: 155-167.

[10] Aleman A, Kahn RS \& Selten JP. Sex differences in the risk of schizophrenia: evidence from meta-analysis. Arch Gen Psych. 2003; 60: 565-571.

[11] Kirkbride JB et al. Heterogeneity in incidence rates of schizophrenia and other psychotic syndromes: findings from the 3-center AESOP study. Arch Gen Psych. 2006; 63: 250-258.

[12] Kirkbride JB et al. Neighbourhood variation in the incidence of psychotic disorders in Southeast London. Soc Psych Epidemiol. 2007; 42: 438-445.

[13] EtichaT, Teklu A, Ali D, Solomon G, Alemayehu A. Factors associated with medication adherence among patients with schizophrenia in Mekelle, Northern Ethiopia. PLoS One. 2015; $10, \mathrm{e} 0120560$.

[14] Arafat SMY, Mali B, Akter H. Proportion and reasons for medication non-compliance among schizophrenics: a crosssectional observation in a tertiary care hospital of Bangladesh. Asian J Psychiatr. 2018; 35: 52-54.

[15] Nuechterlein KH et al. The early course of schizophrenia and long-term maintenance neuroleptic therapy. Arch Gen Psychiatry. 1995; 52: 203-205.

[16] Robinson D et al. Predictors of relapse following response from a first episode of schizophrenia or schizoaffective disorder. Arch Gen Psychiatry. 1999; 56: 241-247.

[17] Wunderink $\mathrm{L}$ et al. Guided discontinuation versus maintenance treatment in remitted first-episode psychosis: relapse rates and functional outcome. J Clin Psychiatry. 2007; 68: 654-661.

[18] Chen EY et al. Maintenance treatment with quetiapine versus discontinuation after one year of treatment in patients with remitted first episode psychosis: randomized controlled trial. BMJ. 2010; 341: c4024.

[19] Gaebel W et al. Relapse prevention in first-episode schizophrenia-maintenance vs intermittent drug treatment with prodrome-based early intervention: results of a randomized controlled trial within the German Research Network on Schizophrenia. J Clin Psychiatry. 2011; 72: 205-218.

[20] Caseiro O et al. Predicting relapse after a first episode of nonaffective psychosis: a three-year follow-up study. $J$ Psychiatr Res. 2012; 46: 1099-1105.

[21] Kane JM, Kishimoto T, Correll CU. Non-adherence to medication in patients with psychotic disorders: epidemiology, contributing factors and management strategies. World Psychiatry. 2013; 12: 216-226.

[22] Birnbaum M, Sharif Z. Medication adherence in schizophrenia: patient perspectives and the clinical utility of paliperidone ER. Patient Prefer Adherence. 2008; 2: 233-240. 
[23] Teferra S, Hanlon C, Beyero T, Jacobsson L, Shibre T. Perspectives on reasons for non-adherence to medication in persons with schizophrenia in Ethiopia: a qualitative study of patients, caregivers and health workers. BMC Psychiatry 2013; 13: 168 .

[24] McCreadie R, Robinson ADG. The Nithsdale schizophrenia survey. VI. Relatives' expressed emotion: prevalence, patterns, and clinical assessment. Br J Psychiatry 1987; 150: 640-644.

[25] Butzlaff RL, Hooley JM. Expressed emotion and psychiatric relapse: a meta-analysis. Arch Gen Psychiatry. 1998; 55: 54752.

[26] Beards S et al. Life events and psychosis: a review and metaanalysis. Schizophr Bull. 2013; 39: 740-747.
[27] Norman RM, Malla AK. Stressful life events and schizophrenia:a review of the research. Br J Psychiatry. 1993; 162: 161-166.

[28] Xu B, Roos JL, Dexheimer P, Boone B, Plummer B, Levy S et al. Exome sequencing supports a denovo mutational paradigm for schizophrenia. Nature Genetics. 2011 Aug 7; 43 (9): 864868.

[29] Neuchterlein KH, Dawson ME. Aheuristic vulnerability/ stress model of schizophrenic episodes. Schizophr Bull. 1984, 10 (2): 300-312.

[30] Cotter D, Pariante CM. Stress and the progression of the developmental hypothesis of schizophrenia. Br J Psychiatry. 2002 Nov; 181: 363-365. 